\title{
Chronic lung disease and pulmonary hypertension: yes or no to $\mathrm{NO}$ ?
}

\author{
Nicholas Curzen, Stephen Archer
}

Nitric oxide (NO) is synthesised in vivo from the semiessential amino acid, L-arginine. It is a small uncharged molecule with an unpaired electron, making it rapidly diffusible through cell membranes but highly reactive. It is a vasodilator, this effect being achieved following activation of soluble guanylyl cyclase after binding to its haem moiety, with a resultant increase in intracellular cyclic guanosine monophosphate (cGMP). ${ }^{1}$ Endogenous NO appears to make an important contribution to the maintenance of vascular tone in many species, including man. In particular, infusion of the nitric oxide synthase inhibitor, L-NMMA, in man leads to an increase of approximately $40 \%$ in pulmonary vascular resistance (PVR) and a $60 \%$ increase in systemic vascular resistance (SVR). ${ }^{2} \mathrm{NO}$ is, in many ways, well equipped to be employed as a selective vasodilator in the lung. The ability to administer NO/air/ oxygen mixtures in a controlled fashion has led to an ever expanding utilisation of this agent both as a research tool and as a treatment. In particular, the administration of NO by inhalation to patients with sepsis complicated by acute lung injury (ALI) or acute respiratory distress syndrome (ARDS) has proved to be an elegant concept by which dilatation of pulmonary vasculature only occurs in areas of the lung that are ventilated. ${ }^{3}$ The improved blood flow through the lungs can therefore be targeted to areas that were best able to oxygenate it, hence reducing ventilation/perfusion $(\mathrm{VA} / \mathrm{Q})$ mismatch whilst simultaneously reducing PVR and often improving right ventricular performance. ${ }^{4}$ Perhaps most elegant of all, upon reaching the blood NO is rapidly inactivated by its avid binding to haem, thereby removing its potential for deleterious systemic vasodilation. Inhaled $\mathrm{NO}$ is now being employed extensively in this context with considerable reported success, despite the lack of hard evidence in the form of randomised controlled trials, as well as concerns over safety. ${ }^{5}$ Although the results of the first clinical trials assessing inhaled NO therapy in the context of persistent pulmonary hypertension of the newborn are due to be published within the next 12 months ${ }^{67}$ similar trials are awaited in adults.

The intellectual appeal of the therapeutic use for NO in ALI overshadows our lack of a clear understanding of the role of endogenous $\mathrm{NO}$ in fundamental physiological and pathophysiological reactions, central to which is hypoxic pulmonary vasoconstriction (HPV). In teleological terms we assume HPV is a beneficial reaction by which VA/Q matching is continuously maintained, but as yet the underlying mechanism is incompletely understood. The role of NO in HPV is gradually becoming clearer. Theoretically, a reduction in NO production or a decrease in its target receptor sensitivity could cause or exacerbate vasoconstriction during hypoxia. Certainly, the contraction induced by hypoxia in isolated human lobar arteries is potentiated by endothelial removal. ${ }^{8}$ Further, in isolated perfused lung preparations inhibition of NO release under hypoxic conditions potentiates pressor responses. ${ }^{9}$ These results are consistent with observations suggesting that endothelium-derived relaxing factor (EDRF) activity ${ }^{1011}$ and NO synthesis ${ }^{12}$ are enhanced in hypoxia. Thus, whilst we have a reasonable understanding of the mechanism of $\mathrm{HPV}^{13}$ and the interaction between $\mathrm{NO}$ and $\mathrm{HPV},{ }^{14}$ the paper by Katayama et $a l^{15}$ in this issue of Thorax raises important questions as to the role of HPV in normal and abnormal lungs. They found that inhaled NO at a concentration of $40 \mathrm{ppm}$ precipitated small but significant reductions in arterial oxygen tension $\left(\mathrm{TcPO}_{2}\right)$ in both healthy volunteers and in patients with chronic obstructive pulmonary disease (COPD). There was no effect on $\mathrm{TcPo}_{2}$ in patients with pulmonary hypertension unrelated to lung disease.

The study raises some interesting issues, but there are some concerns regarding the methods. All the changes observed were of a small magnitude and were obtained in small numbers of subjects using a non-invasive technique that may be more fallible than direct measurement of arterial blood gas tensions. Nevertheless, the authors speculate that the results from the first two groups indicate that inhaled NO may be "overriding" HPV in both patients with COPD and in normal subjects. These results are consistent with those of prior studies. In one previous report a group of patients with COPD whose pulmonary artery pressures (Ppa) were raised were found to respond to $40 \mathrm{ppm}$ of NO with a decrease in their Ppa together with a fall in $\mathrm{SaO}_{2} \cdot{ }^{16}$ The latter observation was explained by a demonstrable deterioration in $\mathrm{VA} / \mathrm{Q}$ distributions following the NO. In another study on 14 patients with COPD who were chronically hypoxic and whose resting PVR and Ppa were raised, $15 \mathrm{ppm}$ NO produced a reduction in both of these parameters that was proportional to the baseline Ppa ${ }^{17}$ Whilst there were no overall changes in the blood gas tensions or dispersion of ventilation and blood flow distributions during NO therapy, there was an increase in the percentage of ventilation in poorly and unperfused areas. Taken together, these studies imply that inhaled NO is unlikely to be of benefit in patients with COPD, although the precise explanation for the lack of benefit is not yet clear. The most logical explanation, supported by at least some of the data, is that NO upsets the abnormal VA/Q balance that is achieved in the lungs of these patients, perhaps by vasodilation in partially constricted areas with reduced ventilation and possibly also by dilation of airways in underperfused areas, as suggested by the paper of Moinard et al. ${ }^{17}$ In fact, this explanation probably extends to other types of vasodilator. For example, a recent study on patients who were on assisted ventilation for COPD demonstrated that prostacyclin also produced detrimental changes in $\mathrm{PaO}_{2} \cdot{ }^{18}$ In contrast to the trials of NO therapy in patients with COPD mentioned above, a study of 13 patients with COPD and pulmonary hypertension found not only a reduction in Ppa with $40 \mathrm{ppm}$ $\mathrm{NO}$, but also a significant increase in $\mathrm{PaO}_{2}$ at the same $\mathrm{FiO}_{2} \cdot{ }^{19} \mathrm{It}$ is tempting to speculate that the reason for these discrepant results is that the population being studied under the collective label of chronic obstructive pulmonary/ airways disease are in fact a highly heterogeneous group. In contrast to the statement by Katayama et al that "patients with COPD do not have high values of PVR..", some 
of the patients in the other studies, whose pulmonary haemodynamics were actually measured, did have increased Ppa and PVR, although this was often mild. These differences are likely to reflect variable pathophysiological responses, both in terms of ventilation and pulmonary vascular tone and structure, to the same chronic hypoxic insults. There can, however, be no doubt that the initial $\mathrm{VA} / \mathrm{Q}$ relationships in these patients with COPD are entirely dissimilar from those of patients with acute respiratory failure and lung injury.

The results in normal volunteers are harder to explain. Whilst it is easy to accept the hypothesis that a degree of HPV is present even in healthy individuals, it is more difficult to understand why the NO could worsen $\mathrm{VA} / \mathrm{Q}$ matching. One interesting possibility is that there are regions even in the normal lung where there is partial ventilation and (appropriately) reduced perfusion. In these areas, the arrival of NO could effectively worsen shunting by increasing blood flow without increasing ventilation. In another study in which healthy volunteers were subjected to an inspired oxygen concentration of $12 \%$ the PVR was increased, presumably due to $\mathrm{HPV}^{20}$ The addition of $40 \mathrm{ppm}$ NO to this inhaled gas mixture reduced the Ppa to baseline without changing the $\mathrm{PaO}_{2}$. In the study by Katayama et al, however, $40 \mathrm{ppm} \mathrm{NO}$ in $21 \% \mathrm{Fio}_{2}$ had no effect on PVR or $\mathrm{PaO}_{2}$. We appear to have only an incomplete understanding of the relationship between inspired gas concentrations, ventilation, and blood flow distribution in the lung.

In the case of patients with pulmonary hypertension not caused by lung disease we are again looking at a highly heterogeneous group. It seems clear that in patients with primary pulmonary hypertension and in those with pulmonary hypertension secondary to cardiac disease there is a subgroup who respond to inhaled $\mathrm{NO}$ with a reduction in Ppa and a second subgroup who are non-responders. ${ }^{21}$ In these patients there are two main treatment objectives in the use of inhaled NO - firstly, to reduce PVR in order to prevent a terminal decline into cardiac failure and, secondly, to improve $\mathrm{PaO}_{2}$. In this sense they are therefore similar to the patients with ALI with raised PVR, and dissimilar to patients with COPD without pulmonary hypertension, in whom improved gas exchange is the sole objective of inhaled NO therapy. A lack of effect on gas exchange in patients with pulmonary hypertension suggests that the underlying problem is not one of $\mathrm{VA} / \mathrm{Q}$ mismatching or that NO cannot reverse existing pulmonary constriction.

Through our considerable enthusiasm for the (still preliminary) results of inhaled NO in patients with ALI/ARDS and raised PVR, we have realised that we now hold a powerful therapeutic weapon. However, it is clear that, even in the normal lung, our understanding of the interaction between ventilation and perfusion of the lung is incomplete. In patients with COPD and pulmonary hypertension, in whom evidence suggests that these $\mathrm{VA} / \mathrm{Q}$ relationships are altered and are even more complex, we require further data to distinguish on which subgroups this therapeutic tool should be used and those in whom it may prove detrimental.

Correspondence to: Dr N Curzen.

Department of Cardiology,

NICHOLAS CURZEN

Royal Brompton Hospital and

National Heart and Lung Institute,

London SW3 6NP, UK

Minneapolis VA Medical Centre,

Minneapolis, Minnesota, USA

STEPHEN ARCHER

1 Moncada S, Palmer RM, Higgs EA. Nitric oxide: physiology, pathophysiology and pharmacology. Pharmacol Rev 1991;43:109-42.

2 Greenberg B, Rhoden K, Barnes PJ. Endothelium-dependent relaxation of human pulmonary arteries. Am f Physiol 1987;252:H434-8.

3 Brett SJ, Evans TW. Inhaled vasodilator therapy in acute lung injury - first do NO harm? Thorax 1995;50:821-3.

4 Rossaint R, Slama K, Steudel W, Gerlach H, Pappert D, Veit S, et al. Effects of inhaled nitric oxide on right ventricular function in severe acute Effects of inhaled nitric oxide on right ventricular function in severe acu
respiratory distress syndrome. Intensive Care Med 1995;21:197-203.

respiratory distress syndrome. Intensive Care Med 1995;21:197-203.
5 Warren JB, Higenbottam T. Caution with use of inhaled nitric oxide. Lancet 1996;348:629-30.

6 Kinsella JP, Truog WE, Walsh WF, Goldberg RN, Bancalari E, Clark RH, et al. Randomised, multicenter trial of inhaled NO and high frequency oscillatory ventilation in severe persistent pulmonary hypertension of the newborn. Pediatr Res 1996;39:222A.

7 Wessels D, Adatia I, Thompson J, Kane J, VanMarten L, Stark A, et al. Improved oxygenation in a randomized trial of inhaled nitric oxide for PPHN. Pediatr Res 1996;39:252A.

8 Ohe M, Ogata M, Shirato K, Takishima T. The role of endothelium in the hypoxic contraction of isolated human pulmonary artery. Circulation 1987 76(Suppl II):467.

9 Mazmanian G, Baudet B, Brink C, et al. Methylene blue potentiates vascular reactivity in isolated rat lungs. F Appl Physiol 1989;66:1040-5.

10 Russ RD, Walker BR. Maintained endothelium-dependent pulmonary vasodilation following chronic hypoxia in the rat. 7 Appl Physiol 1993;74: 339-44.

11 Isaacson TC, Hampl V, Weir EK, Nelson DP, Archer SL. Increased endothelium-derived nitric oxide in hypertensive pulmonary circulation of thelium-derived nitric oxide in hypertensive pulmonar
chronically hypoxic rats. $\mathcal{F}$ Appl Physiol 1994;76:933-40.

12 Hampl V, Cornfield D, Cowan N, Archer SL. Hypoxia potentiates nitric oxide synthesis and transiently increases cytosolic calcium levels in pulmonary artery endothelial cells. Eur Respir f 1995;8:515-22.

13 Post J, Hume J, Archer S, Weir EK. Direct role for potassium channel inhibition in hypoxic pulmonary vasoconstriction. Am F Physiol 1992;262 C882-90

14 Archer S1, Huang JMC, Reeve HL, Hampl V, Tolarova S, Michelakis E, et al. Differential distribution of electrophysiologically distinct myocytes in conduit and resistance arteries determines their response to nitric oxide and hypoxia. Circ Res 1996;78:431-42.

15 Katayama Y, Higenbottam TW, Diaz de Atauri MJ, Cremona G, Akamine $\mathrm{S}$, Barbera JA, et al. Inhaled nitric oxide and arterial oxygen tension in patients with chronic obstructive pulmonary disease and severe pulmonary hypertension. Thorax 1997;52:120-4.

16 Barbera JA, Roger N, Roca J, Rovira I, Higenbottam TW, Rodriguez-Roisin $\mathrm{R}$. Worsening of pulmonary gas exchange with nitric oxide inhalation in $\mathrm{R}$. Worsening of pulmonary gas exchange with nitric oxide inhalatio
chronic obstructive pulmonary disease. Lancet 1996;347:436-40.

17 Moinard J, Manier G, Pillet O, Castaing Y. Effect of inhaled nitric oxide on hemodynamics and VA/Q inequalities in patients with chronic obstructive hemodynamics and $\mathrm{VA} / \mathrm{Q}$ inequalities in patients with chronic obst
pulmonary disease. Am $\mathcal{F}$ Respir Crit Care Med 1994;149:1482-7.

18 Archer SL, Mike D, Crow J, Long W, Weir EK. A placebo controlled trial of prostacyclin in acute respiratory failure in chronic obstructive lung of prostacyclin in acute respirator
disease. Chest 1996;109:750-5.

19 Adnot S, Kouyoumdjian C, Defouilloy C, Andrivet P, Sediame S, Herigault $\mathrm{R}$, et al. Hemodynamic and gas exchange responses to infusion of acetylcholine and inhalation of nitric oxide in patients with chronic obstructive lung disease and pulmonary hypertension. Am Rev Respir Dis 1993;148: 310-6.

20 Frostell CG, Blomqvist H, Hedenstierna G, Lundberg J, Zapol WM. Inhaled nitric oxide selectively reverses human hypoxic pulmonary vasoconstriction without causing systemic vasodilatation. Anesthesiology 1993;78:427-35.

21 Sitbon O, Brenot F, Denjean A, Bergeron A, Parent F, Azarian R, et al. Inhaled nitric oxide as a screening vasodilator agent in primary pulmonary hypertension. Am J Respir Crit Care Med 1995;151:384-9. 